\section{The adrenal capsule is a signaling center controlling cell renewal and zonation through Rspo3}

\author{
Valerie Vidal, ${ }^{1,2,3,9}$ Sonia Sacco, ${ }^{1,2,3,9}$ \\ Ana Sofia Rocha, ${ }^{1,2,3,8}$ Fabio da Silva, ${ }^{1,2,3}$ \\ Clara Panzolini, ${ }^{1,2,3}$ Typhanie Dumontet, ${ }^{4,5}$ \\ Thi Mai Phuong Doan, ${ }^{1,2,3}$ Jingdong Shan, ${ }^{6}$ \\ Aleksandra Rak-Raszewska, ${ }^{6}$ Tom Bird, ${ }^{7}$ \\ Seppo Vainio, ${ }^{6}$ Antoine Martinez, ${ }^{4,5}$ \\ and Andreas Schedl ${ }^{1,2,3}$
}

\begin{abstract}
${ }^{1}$ Institute of Biology Valrose, Université de Nice-Sophia, F-06108 Nice, France; ${ }^{2}$ UMR1091, Institut National de la Santé et de la Recherche Médicale, F-06108 Nice, France; ${ }^{3}$ CNRS, UMR7277, F-06108 Nice, France; ${ }^{4}$ UMR6293, Centre National de la Recherche Scientifique, Clermont Université, F-63178 Aubière, France; ${ }^{5}$ U1103, Institut National de la Santé et de la Recherche Médicale, Clermont Université, F-63178 Aubière, France; ${ }^{6}$ Biocenter Oulu, 90220 Oulu, Finland; ${ }^{7}$ Beatson Institute, Glasgow G61 1BD, United Kingdom
\end{abstract}

Adrenal glands are zonated endocrine organs that are essential in controlling body homeostasis. How zonation is induced and maintained and how renewal of the adrenal cortex is ensured remain a mystery. Here we show that capsular RSPO3 signals to the underlying steroidogenic compartment to induce $\beta$-catenin signaling and imprint glomerulosa cell fate. Deletion of RSPO3 leads to loss of SHH signaling and impaired organ growth. Importantly, Rspo3 function remains essential in adult life to ensure replenishment of lost cells and maintain the properties of the zona glomerulosa. Thus, the adrenal capsule acts as a central signaling center that ensures replacement of damaged cells and is required to maintain zonation throughout life.

Supplemental material is available for this article.

Received January 12, 2016; accepted in revised form May 16, 2016.

The mammalian adrenal gland is derived from the adrenal primordium, a precursor of the adrenal cortex that becomes invaded by neural crest cells, which will later form the adrenal medulla. By embryonic day 12.5 (E12.5) in mice, the developing organ becomes surrounded by condensing mesenchymal cells that ultimately form the capsule (Bandiera et al. 2013). A second contribution to the capsule is likely derived from adrenal progenitor cells that have lost SF1 expression (Wood et al. 2013).

[Keywords: R-spondin signaling; adrenal zonation; $\beta$-catenin signaling; mouse models; organ maintenance]

${ }^{8}$ Present address: Beatson institute, Glasgow G61 1BD, UK.

'These authors contributed equally to this work.

Corresponding author: schedl@unice.fr

Article published online ahead of print. Article and publication date are online at http://www.genesdev.org/cgi/doi/10.1101/gad.277756.116.
The permanent cortex is formed through recruitment of capsular cells in a process that involves SHH signaling (King et al. 2009). By E17.5, steroidogenic cells have adopted specific expression profiles, with the outermost cell layers (zona glomerulosa [ZG]) producing enzymes that are required for mineralocorticoid production (e.g., CYP11B2), and deeper layers (zona fasciculata [ZF]) expressing genes involved in glucocorticoid synthesis (Сур11b1). In humans, but not rodents, a third layer (zona reticularis) can be distinguished that produces androgens and is located close to the medulla. Several lines of evidence suggest that $\beta$-catenin plays an important role in adrenal zonation and maintenance. Activation of the $\beta$-catenin pathway is restricted to the ZG (Kim et al. 2008; Walczak et al. 2014), and ectopic expression leads to the activation of ZG markers in ZF cells (Berthon et al. 2010). Moreover, $\beta$-catenin seems to bind to and control the expression of $A t 1 r$, a gene specifically expressed within the ZG (Berthon et al. 2014). Finally, stochastic deletion of $\beta$-catenin using a low-level expressing Sf1Cre line leads to progressive loss of the adrenal cortex in adult life (Kim et al. 2008).

\section{Results and Discussion}

Recent lineage tracing studies have revealed that adrenal maintenance likely involves cell conversion of ZG cells into ZF cells (Freedman et al. 2013), with cells being displaced in a centripetal fashion. In our search for signaling molecules that may be involved in adrenal cell renewal and zonation, we identified members of the $R$-spondin gene family to be expressed from E12.5 onward within mesenchymal cells surrounding the forming adrenal (Supplemental Fig. S1). Expression of Rspo1 and Rspo3 was maintained throughout development and well into adulthood (Fig. 1A; Supplemental Fig. S1A). R-spondins are signaling molecules that bind to LGR receptors and positively modulate the $\beta$-catenin signaling pathway (de Lau et al. 2014). As expected from previous studies, $\beta$-catenin was highly expressed in the ZG (Fig. 1B). Moreover, immunofluorescence analysis revealed LGR5 to be enriched within ZG cells (Fig. 1B), which is consistent with an active RSPO/LGR5/ $\beta$-catenin cascade.

The adrenal capsule consists of mesenchymal cells that are positive for the SHH mediator GLI1 (King et al. 2009) and COUPTFII (also known as NR2F2) (Wood et al. 2013) and surrounded by a thin layer of mesothelial lining expressing the Wilms tumor suppressor WT1 (Bandiera et al. 2013). To determine whether Rspo1 and Rspo3 are expressed in the same cell population, we performed cell-sorting experiments on dissociated adult adrenals from Wt1-GFP animals (Hosen et al. 2007). Quantitative PCR (qPCR) analysis revealed the majority of Rspo1 expression to be within the $\mathrm{WT}^{+}$population (Supplemental Fig. S1D), which is consistent with previously published data showing a direct regulation of this gene by this

(C) 2016 Vidal et al. This article is distributed exclusively by Cold Spring Harbor Laboratory Press for the first six months after the full-issue publication date (see http://genesdev.cshlp.org/site/misc/terms.xhtml). After six months, it is available under a Creative Commons License (Attribution-NonCommercial 4.0 International), as described at http://creativecommons.org/licenses/by-nc/4.0/. 

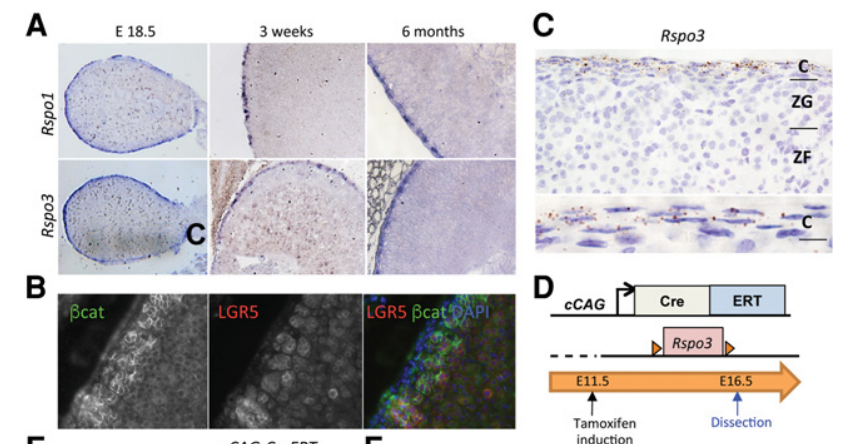

E

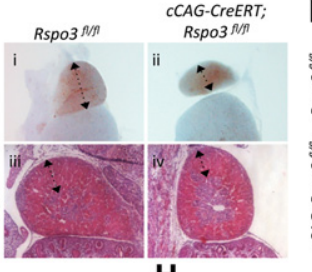

G

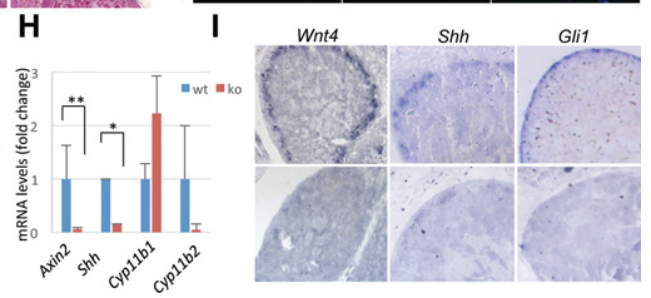

Figure 1. Rspo3 is expressed in the adrenal capsule and is required for adrenal growth and the onset of zonation. $(A)$ In situ hybridization (ISH) analysis reveals Rspo1 and Rspo3 in the capsule surrounding the adrenal cortex. (B) Immunostaining showing the LGR5 receptor to be enriched in ZG cells that also show strong staining for $\beta$-catenin. (C) RNA-Scope analysis on adult adrenals. (D) Schematic outline of the experimental strategy used. Rspo3 was deleted by injecting tamoxifen into pregnant mothers at E11.5 and collecting embryos at E16.5. (E) Macroscopic analysis (panels i,ii) and hematoxylin and eosin $(\mathrm{H} \& \mathrm{E}$ ) staining (panels iii,iv) demonstrate a dramatic reduction of adrenal size in the absence of Rspo3 expression. (CAG) cCAGCreERT. $(F)$ Immunofluorescent analysis shows a reduction of adrenal cortex (SF1-positive cells; green) but not medullary ( $\mathrm{TH}$; light blue) cells. (G) Quantification of SF1-positive cells confirms dramatic loss of the steroidogenic compartment. $n_{\mathrm{wt}}=4 ; n_{\mathrm{ko}}=4 ; P=8 \times 10^{-4}$, Student's $t$-test. $(H)$ Quantitative PCR (qPCR) analysis of RNA extracted from E16.5 adrenals. $n_{\mathrm{wt}}=3 ; n_{\mathrm{ko}}=4$; Axin2, $P=9 \times 10^{-3}$; Shh, $P=0.02$. (I) ISH analysis shows complete loss of Wnt4, Shh, and Gli1 expression.

transcription factor (Motamedi et al. 2014). In contrast, Rspo3 appeared to be in a distinct cell population that does not express high levels of WT1. RNA-Scope analysis revealed Rspo3 to be expressed throughout the capsule (Fig. 1C), reminiscent of the expression pattern of Gli1 (King et al. 2009) and NR2F2/COUPTFII (Wood et al. 2013). To test whether Rspo3-expressing cells may be identical to the Gli1-positive population, we used a Gli1-CreERT2 line in combination with a conditional allele for Rspo3 (Rocha et al. 2015). Deletion was induced at E14.5 by tamoxifen induction, and samples were collected at E16.5 (Supplemental Fig. S1E). Strikingly, RNA expression analysis showed an almost $70 \%$ reduction after deletion, indicating that Gli1- and Rspo3-expressing cells are largely identical (Supplemental Fig. S1F).

We next used genetic analysis to address whether $R$-spondins may play a direct role in adrenal formation and homeostasis. Deletion of Rspo1 was compatible with survival (Chassot et al. 2008; Tomizuka et al. 2008) and had no significant effect on adrenal development, zonation, or tissue maintenance (Supplemental Fig. S2). Rspo3-deficient embryos die early in development due to defects in placenta formation (Kazanskaya et al. 2008). We therefore resorted to a tamoxifen-inducible approach (Fig. 1D) combining the Rspo3 ${ }^{\text {flox }}$ allele (Rocha et al. 2015) with the ubiquitously expressed cCAGCreERT driver strain (Hayashi and McMahon 2002). Induced deletion of Rspo3 at E11.5 resulted in smaller adrenals and thinning of the adrenal cortex at E16.5 (Fig. 1E). Indeed, quantitation of SF1-positive cells revealed a 2.5fold decrease of the adrenal steroidogenic compartment in the absence of Rspo3 (Fig. 1F,G).

The dramatic reduction of $\mathrm{SF} 1^{+}$cells in $R$ spo3 knockout animals indicated an important function for this gene in the formation of the adult adrenal cortex. Previous studies have demonstrated a key role for SHH signaling in the recruitment of capsular $\mathrm{Gli1}^{+}$cells to the steroidogenic lineage (Ching and Vilain 2009; King et al. 2009; Huang et al. 2010), and Shh has been suggested to be regulated by canonical $\beta$-catenin signaling in the adrenal system (Drelon et al. 2015) and several other developmental systems (Iwatsuki et al. 2007; Ahn et al. 2010). To test whether this pathway is affected in Rspo3 mutants, we carried out qPCR, immunohistochemistry, and in situ hybridization (ISH) analysis on E16.5 tissues. Deletion resulted in a near-complete loss of the $\beta$-catenin target Axin2 (Lustig et al. 2002), thus indicating a requirement of Rspo3 for canonical signaling (Fig. 1H). Shh was prominently expressed in steroidogenic cells juxtaposing the capsule of control animals but became almost undetectable in Rspo3 mutant animals (Fig. 1H,I). Consistent with the loss of SHH signaling, expression of its direct target, Gli1, also disappeared from capsular cells after Rspo3 deletion (Fig. 1I). Wnt4, a gene that has been shown to be directly regulated by $\beta$-catenin in the kidney (Park et al. 2012), was no longer expressed in the mutant cortex (Fig. 1I).

Taken together, these data suggest a double-paracrine mechanism in adrenal cortex development, in which RSPO3 is released from the capsule to induce $\beta$-catenin signaling within juxtaposed steroidogenic cells, leading to the activation of Shh. In turn, SHH signals back to capsular cells, where it activates Gli1 and other downstream targets to recruit cells to the steroidogenic lineage. Loss of Rspo3 signaling leads to lack of cell recruitment and, as a consequence, a severely reduced adrenal cortex.

Zonation of the adrenal cortex into ZG and ZF commences at around E16.5 in mice and has been suggested to depend on $\beta$-catenin signaling. Ubiquitous deletion of Rspo3 at E11.5 results in heart failure (F Da Silva, AS Rocha, J Ryler, C Basboga, H Morrison, KD Wagner, and A Schedl, in prep.), thus prohibiting the analysis of later time points. We therefore resorted to the capsular-expressed Gli1-CreERT2 strain and induced deletion at E13.5, which resulted in a lack of Rspo3 expression at E18.5 (Fig. 2A,B). Immunofluorescent analysis revealed loss of the ZG-specific marker DAB2 (Fig. 2C). In contrast, expression of the ZF-specific markers AKR1B7 and CYP11B1 persisted and now extended throughout the remaining cortex up to the capsule. BrdU labeling experiments confirmed an almost complete loss of proliferation in the adrenal cortex, whereas dividing cells persisted in other tissues (Supplemental Fig. S3). NR2F2 expression persisted in the capsule (Fig. 2C), although the number of cells also appeared to be somewhat reduced. 
A

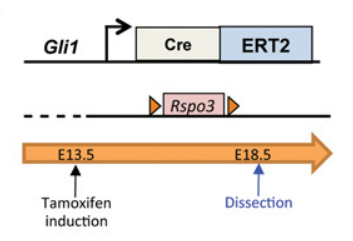

C

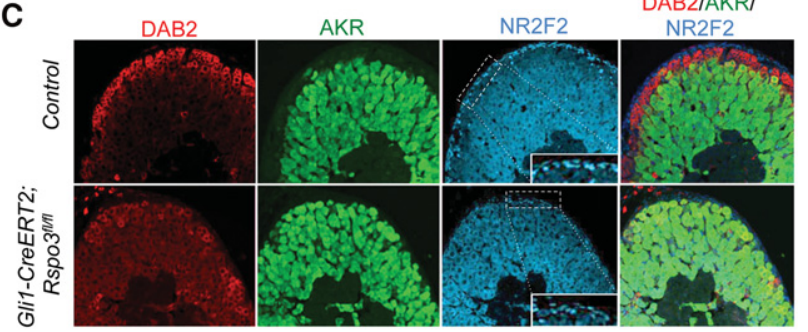

B

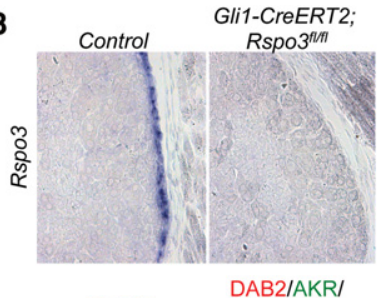

D
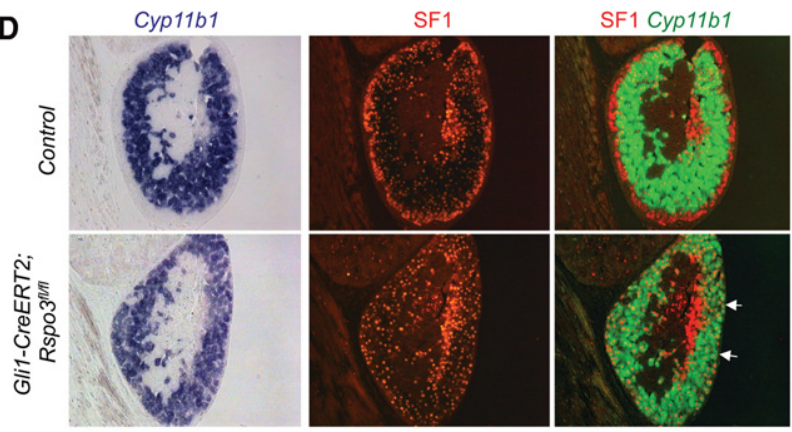

Figure 2. Deletion of RSPO3 interferes with the development of adrenal zonation. (A) Experimental setup using Rspo3f1/fl; Gli1CreERT2 animals. (B) ISH analysis at E18.5 showing the complete loss of Rspo3 expression in mutant animals. (C) Immunofluorescent analysis demonstrates loss of the ZG marker DAB2 and an expansion of AKR1B7 up to the capsule. NR2F2-positive capsular cells are maintained in mutant animals. (D) Cyp11b1 ISH, SF1 antibody staining, and a digital overlay of the two data sets. The ZF marker Cyp11b1 also extends to the capsule in mutant animals (white arrows).

To test whether continuous RSPO3 signaling was required to maintain adrenal homeostasis, we induced Cre recombination (cCAG-CreERT driven) in adult mice $(12 \mathrm{wk})$ and sacrificed animals at various time points after induction (Fig. 3A). ISH confirmed near-complete loss of Rspo3 expression in the adrenal capsule (Fig. 3B; Supplemental Fig. S4B). Adrenal weight in Rspo3 mutants progressively decreased over time and dropped to $50 \%$ of that in control animals $6 \mathrm{wk}$ after induction (Fig. 3C). Histological analyses confirmed a severely reduced adrenal cortex, while the medulla appeared unaffected (Fig. 3D). High-power views revealed loss of the typical ZG organization in arches. Instead, the remaining cortical cells showed the columnar arrangement reminiscent of the ZF. To test whether mutant adrenals showed reduced proliferation, we performed long-term BrdU tracing experiments. In control animals, a large number of SF1/BrdU double-positive cells were detected, indicating that they underwent cell division during the labelling period (Fig. $3 \mathrm{E})$. In contrast, BrdU-labeled cells were dramatically reduced after Rspo3 deletion, and SF1/BrdU double-positive cells were almost absent.

To confirm the loss of ZG differentiation, we next analyzed a range of molecular markers using ISH and immunostaining. Wnt4, Shh, Gli1 (Fig. 4A), DAB2, and CYP11B2 (Fig. 4B,C) were dramatically reduced in mutant mice. Similar to development, the ZF marker AKR1B7 now extended up to the capsule (Fig. 4B). qPCR assays confirmed these findings with no alteration in $\mathrm{ZF}$ markers and an almost complete loss of ZG marker genes (Fig. 4B).

To exclude secondary effects that might have been caused by systemic deletion of Rspo3, we next performed tissue-specific deletion experiments using the Gli1-CreERT2 strain (Supplemental Fig. S4A). qPCR analysis revealed a reduction of Rspo3 expression to $\sim 30 \%$ of wildtype levels, which is somewhat lower than what we observed using the ubiquitously expressed $c C A G$-CreERT line (Supplemental Fig. S4B). The less efficient deletion is likely to be due to lower levels of expression from the Gli1 promoter. Axin2 expression levels closely followed those of Rspo3 (Supplemental Fig. S4A). Importantly, Gli1-CreERT2-specific deletion also caused a reduction of the adrenal cortex and the loss of ZG markers (Supplemental Fig. S4C,D), indicating that, indeed, zonation depends on capsular expression of Rspo3.

The striking loss of ZG markers could be caused by either apoptosis of ZG cells, lack of cell renewal, or a continuous requirement for RSPO3 signaling to specify ZG cells. To distinguish between these alternatives, we analyzed

A
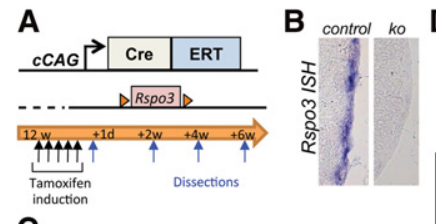

C

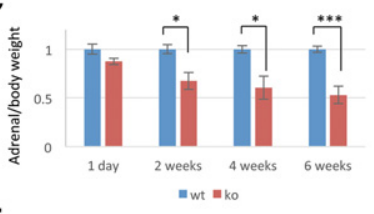

E

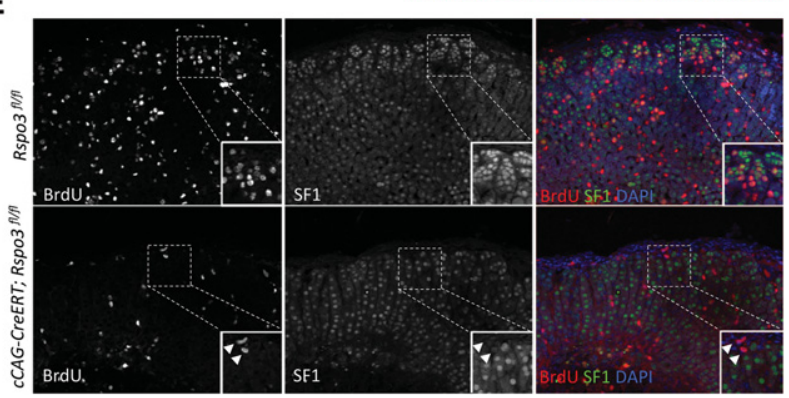

Figure 3. Continuous RSPO3 signaling is required for adrenal homeostasis. (A) Experimental design. Twelve-week-old mice were induced and analyzed at various time points. (B) Analysis at 4 wk demonstrates a complete loss of capsular Rspo3 expression upon tamoxifen induction. $(C)$ Loss of Rspo3 leads to progressive loss of adrenal weight. $1 \mathrm{~d}, n_{\mathrm{wt}}=6, n_{\mathrm{ko}}=6 ; 2 \mathrm{wk}, n_{\mathrm{wt}}=6, n_{\mathrm{ko}}=6 ; 4 \mathrm{wk}, n_{\mathrm{wt}}=4, n_{\mathrm{ko}}$ $=5 ; 6 \mathrm{wk}, n_{\mathrm{wt}}=12, n_{\mathrm{ko}}=15.2 \mathrm{wk}, P=1.5 \times 10^{-3} ; 4 \mathrm{wk}, P=2.6 \times 10^{-3}$; $6 \mathrm{wk}, P=3.0 \times 10^{-8}$, Student's $t$-test. $(D)$ Macroscopic and histological examination (Azan staining) $6 \mathrm{wk}$ after Rspo3 deletion reveals smaller adrenal glands and the dramatic thinning and loss of the ZG typical arrangement of cells in arches (black arrows). (E) BrdU analysis $(40 \mathrm{~d})$ reveals a dramatic loss of proliferation after Rspo3 deletion. The only labeled cells in Rspo3 knockout animals (white arrowheads) are nonsteroidogenic, as indicated by the absence of SF1. 

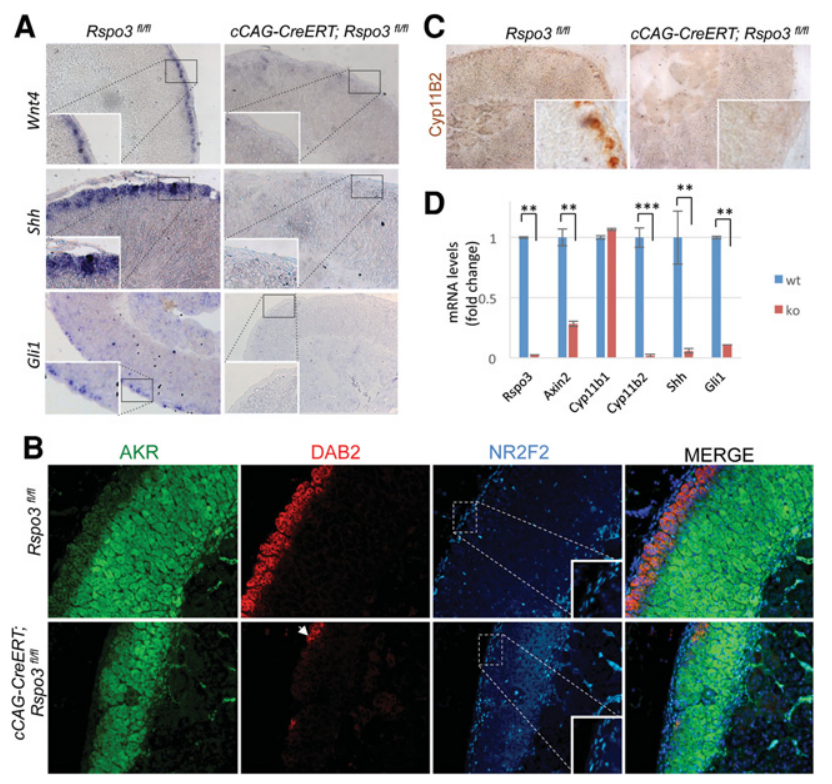

Figure 4. Loss of Rspo3 abolishes adrenal zonation. ISH $(A)$, immunofluorescent $(B)$, and immunohistochemical $(C)$ analyses reveal loss of all ZG-specific markers analyzed. Note the persistence of pockets of DAB2 expression (white arrowhead in $B$ ) that are likely associated with incomplete deletion of Rspo3. (B) NR2F2 capsular cells appear to be largely unaffected. $(D)$ qPCR analysis confirms the dramatic reduction of expression of the $\beta$-catenin target Axin2 and a near loss of ZG markers Cyp11B2 and Shh as well as the capsular marker Gli1. $n_{\mathrm{wt}}=5 ; n_{\mathrm{ko}}=5$. Rspo3, $P=8 \times 10^{-3} ;$ Axin2, $P=1 \times 10^{-3} ;$ Cyp $11 \mathrm{~B} 2$, $P=3 \times 10^{-5}$; Shh, $P=2 \times 10^{-3}$; Gli1, $P=5 \times 10^{-3}$, Student's $t$-test.

samples $1 \mathrm{~d}$ after completion of the tamoxifen deletion protocol (Fig. 5), in which lack of cell renewal can be excluded. Knockout adrenals at this early time point showed only a very mild reduction in size that did not reach statistical significance (Fig. 3C). Caspase3 analysis identified a number of apoptotic cells close to the medulla (Fig. $5 \mathrm{~B}$ ), which is consistent with the centripetal model of cell renewal (Freedman et al. 2013). Deletion of Rspo3 did not increase apoptosis, thus excluding cell death as a reason for the loss of ZG markers. Strikingly, molecular analysis confirmed a near-complete loss of all ZG markers analyzed (Shh, Wnt4, DAB2, and Cyp11b2) even at this early time point after Rspo3 deletion (Fig. 5C). The absence of apoptosis in steroidogenic cells after Rspo3 deletion and the expansion of ZF markers up to the capsule at 4 wk after deletion suggest that ZG cells convert to ZF cells, a process that is also occurring under normal conditions when steroidogenic cells move centripetally, thus losing signals derived from the adrenal capsule (Freedman et al. 2013).

Wnt4 has been demonstrated previously to be required for the activation of Cyp11b2 expression (Heikkila et al. 2002), and we showed recently that this dependence also persists in adult mice (C Drelon, A Berthon, I Sahut-Barnola, M Mathieu, T Dumontet, S Rodriguez, M BatisseLignier, H Tabbal, I Tauveron, AM Lefrançois-Martinez, et al., in prep.). To test whether deletion of Wnt4 may affect RSPO3-controlled signaling pathways and cell renewal, we analyzed Wnt4; Sf1-Cre knockout mice (Supplemental Fig. S5A) that showed efficient depletion of Wnt4 in adrenal glands (Supplemental Fig. S5C). Surprisingly, mice survived into adulthood $(>12 \mathrm{mo})$ with no

overt defects detectable. Adrenals in Wnt4 knockout mice were only slightly smaller (Supplemental Fig. S5B), demonstrating that this gene does not play a major role in cell renewal. Molecular analysis revealed a significant reduction of the ZG markers Axin2 and At1b but only a mild reduction of Rspo3, Shh, and Gli1 expression that did not reach statistical significance (Supplemental Fig. S5C,D). Thus, Wnt4 appears to act as a local relay signal that reinforces $\beta$-catenin activity in the ZG but does not have a major influence on organ renewal.

A recent study suggested RSPO3 to bind to LGR5 and induce noncanonical signaling in adrenal cortical cells. This signaling appeared to inhibit aldosterone production and cell renewal and induce apoptosis (Shaikh et al. 2015). These findings are in stark contrast to the data presented in this study. We presume the discrepancy to be caused by the in vitro setting of the previously reported study, which does not take into account the complex interactions of cells in an in vivo environment. Our data clearly demonstrate a canonical role for Rspo3 signaling within the adrenal cortex, where it induces well-established direct downstream targets of $\beta$-catenin (Axin2 and Dab2) and maintains organ size in the adult organism. This role is consistent with the generally accepted function of RSPO/LGR5 signaling in controlling the activation of the stem cell pool, and we can now add the adrenal cortex as an additional organ in which this pathway is used.

Even more surprising than the involvement of RSPO3 in controlling organ renewal is its absolute requirement for maintaining adrenal zonation. The rapid loss of zonation markers after Rspo3 deletion in the adult demonstrates that it acts as an instructive signal to direct

A
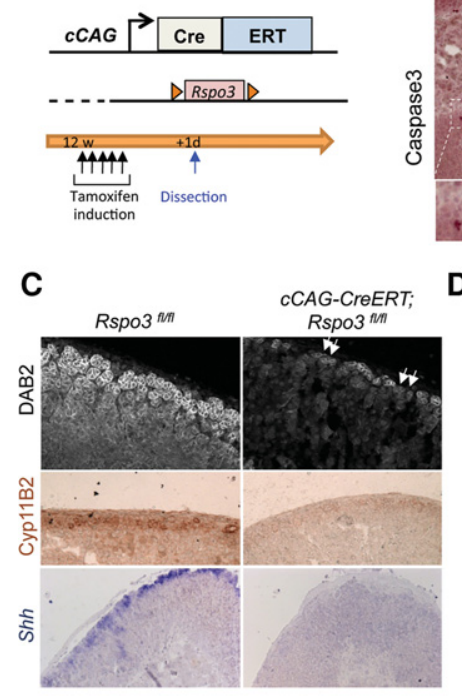

Figure 5. Rspo3 deletion leads to a rapid loss of ZG identity. (A) Experimental design. $(B)$ Caspase staining revealed some apoptotic cells close to the medulla, whereas the ZG was devoid even after deletion of Rspo3. (C) ISH and immunostaining demonstrated a rapid loss of ZG marker gene expression. Note the complete loss of DAB2 in a proportion of subcapsular cells (white arrow) upon Rspo3 deletion. (D) Model describing the central role of Rspo3 in establishing adrenal zonation and ensuring cell renewal. Large red arrows symbolize the centripetal movement of cells during cell renewal. (Meso) Mesothelial lining; $(\mathrm{C})$ capsule. 
steroidogenic cells toward the ZG phenotype. The adrenal capsule is the ideal location to provide this stimulus. Since R-spondins appear to be tightly bound to the extracellular matrix (Kim et al. 2005), diffusion is limited, and only several cell layers are instructed to express ZG markers. Activation of Wnt4 within the ZG cells is likely to serve as a local reinforcement signal, as loss of Wnt4 also leads to a reduction of ZG markers (Supplemental Fig. S5; Heikkila et al. 2002).

Apart from the adrenal cortex, hepatocytes also display metabolic zonation along the liver lobule that is set up by a gradient of canonical $\beta$-catenin signaling (Benhamouche et al. 2006). We showed recently that, in a fashion similar to the adrenal, liver zonation strictly depends on RSPO3 that is released from endothelial cells located in the central vein (Rocha et al. 2015). Thus, our evidence suggests that the liver and adrenal cortex have adopted the same signaling system to establish organ-specific zonation despite the fact that both organs are derived from distinct embryological origins.

In conclusion, our data establish a genetic network in which Rspo3 induces Wnt4 and Shh expression within steroidogenic cells that are in close contact with the capsule (Fig. 5D). Shh in turn signals back to recruit capsular cells to form the adrenal cortex, at least during development. The fact that Shh knockout mice show normal adrenal zonation (Huang et al. 2010) while Rspo3 deletion affects ZG identity indicates that Rspo3 must also act through additional, Shh-independent pathways. The dramatic thinning of the entire steroidogenic compartment further supports the model of a ZG-driven adrenal cortex renewal, a concept that has been put forward by Freedman et al. (2013). Thus, our study identifies the adrenal capsule as a crucial signaling center that, through the production of RSPO3, not only ensures organ renewal but also provides an instructive signal that is continuously required for proper zonation.

\section{Materials and methods}

\section{Mouse work}

All animal work was conducted according to national and international guidelines and was approved by the local ethics committee (PEA-NCE/ 2013-88). The Rspo1 (Chassot et al. 2008), Rspo3flox (Rocha et al. 2015), Wt1-GFP (Hosen et al. 2007), Gli1-CreERT2 (Ahn and Joyner 2004), cCAG-CreERT (Hayashi and McMahon 2002), Sf1-Cre (Bingham et al. 2006), and Wnt $4^{f l o x}$ (Shan et al. 2009) lines have been described previously. Cre activation during development was obtained by a single tamoxifen administration (force feeding) of pregnant females carrying either E11.5, E13.5, or E14.5 embryos. Cre activation in adult mice was obtained by intraperitoneal injection of 12 -wk-old mice with $1 \mathrm{mg}$ of tamoxifen (Sigma-Aldrich) dissolved in corn oil (Sigma-Aldrich) per $20 \mathrm{~g}$ of body weight five times a week for $1 \mathrm{wk}$. With the exception of embryonic analysis, only male mice were used for the described experiments.

For proliferation assays, $1 \mathrm{mg} / \mathrm{mL} \mathrm{BrdU}$ was added to drinking water, the solution was changed every $2 \mathrm{~d}$, and animals were sacrificed at the end of 4 wk of treatment.

\section{Cell sorting}

Adrenals from adult WT1GFP or control animals were collected and incubated for $30 \mathrm{~min}$ in $1 \mathrm{mg} / \mathrm{mL}$ collagenase at $37^{\circ} \mathrm{C}$, and the adrenal capsule was separated from the rest of the adrenal using a binocular microscope. After a further $30 \mathrm{~min}$ of incubation in trypsin at $37^{\circ} \mathrm{C}$ with occasional pipetting up and down, the digestion was stopped by adding $100 \mu \mathrm{L}$ of FBS, and the cell suspension was filtered (40- $\mu \mathrm{m}$ filters), centrifuged (2000 rpm for $3 \mathrm{~min}$ ), and resuspended in $200 \mu \mathrm{L}$ of PBS-EDTA-serum solution. Cells were analyzed with a FACS Aria II (BD).

\section{Immunofluorescence and histological analysis}

For immunofluorescence experiments, tissues were fixed overnight in $4 \%$ paraformaldehyde, progressively dehydrated, and paraffin-embedded. Seven-micrometer-thick sections were rehydrated, boiled in a pressure cooker for 2 min with antigen unmasking solution (Vector Laboratories), and blocked in a PBS solution containing 10\% normal donkey serum (Jackson Immunoresearch) and 3\% BSA. All primary antibodies were applied overnight at $4^{\circ} \mathrm{C}$ at the concentrations listed in the antibody table in the Supplemental Material. Secondary antibodies were diluted 1:200 and applied at room temperature for $1 \mathrm{~h}$. $\beta$-Catenin was detected using a biotinylated secondary antibody followed by streptavidin-Cy3 detection (Sigma-Aldrich).

For histological analysis, adrenal glands from embryos or adult mice were fixed overnight in $4 \%$ paraformaldehyde, progressively dehydrated and embedded in paraffin. Seven-micrometer-thick sections were then stained with hematoxylin and eosin according to standard procedures.

For CYP11B2 and caspase 3 staining, sections were unmasked, incubated for $30 \mathrm{~min}$ in $\mathrm{H}_{2} \mathrm{O}_{2}(30 \%)$, and blocked for $1 \mathrm{~h}$ in $5 \%$ PBS/BSA. Primary antibody was left overnight at $4{ }^{\circ} \mathrm{C}$ in $0.1 \%$ PBS/BSA, and polymer-Hrp rabbit (Cell Signaling, 8114) was used as a secondary and incubated for $30 \mathrm{~min}$ at room temperature. Revelation was performed with a Novared kit (Vector Laboratories) for $4 \mathrm{~min}$.

\section{Azan staining}

Histological sections at $5 \mu \mathrm{m}$ were stained using the Azan trichrome kit (Diapath) according to the manufacturer's instructions.

\section{RNA ISH}

Tissues were fixed overnight in $4 \%$ paraformaldehyde, progressively dehydrated, and paraffin-embedded. The Gli1 in situ probe was kindly provided by M. Studer (Institute of Biology Valrose, Université de NiceSophia Antipolis). Seven-micrometer-thick sections were hybridized with Rspo1, Rspo3, Wnt4, and Shh as well as Gli1 probes according to previously described protocols (Comai et al. 2010). RNA-Scope analysis for Rspo3 was performed on adult sections according to the manufacturer's instructions.

\section{Real-time PCR analysis}

RNA was extracted from E16.5 or adult adrenal glands using TRIzol reagent (Invitrogen) following the manufacturer's instructions. Reverse transcription was performed using M-MLV reverse transcriptase (Invitrogen) in combination with random primers. The cDNA obtained was then used as template for qPCR analysis using the SYBR Green master kit (Roche) and a LightCycler 1.5 (Roche). The expression levels were normalized for Hprt. Primers (see the primer table in the Supplemental Material) were designed on the Universal ProbeLibrary Web site (Roche).

\section{Statistical analysis}

Statistical significance was determined using two-tailed Student's $t$-test. Error bars in all figures represent the standard error of mean, and $P$-values are indicated by asterisks as follows: $P<0.05\left({ }^{*}\right), P<0.01\left(^{* *}\right)$, and $P<0.001\left(^{(* * *)}\right.$.

For the developmental analysis (Fig. 1G), SF1-positive cells were counted on every second section of four control and four knockout adrenals using Volocity 6.3 software. Statistical analysis was performed with the total of nuclei obtained for each adrenal using a two-tailed Student's $t$-test.

\section{Acknowledgments}

We thank the staff of the animal facility for their dedication, and Agnès Loubat (cytometry platform, iBV) for FACs analysis. We are indebted to Hitoshi Okamoto (Riken Institute, Japan) for providing the Rspo3 conditional allele, and Celso Gomez-Sanchez (Jackson, MS) for the Cyp11B2 antibody. We are grateful to Pierre Val (Clermont Ferrand, France) for critically reading this manuscript, and Roberto Bandiera (Cambridge, UK) for initial input into this project. This work was supported by grants from the Fondation du France, Association pour la Recherche sur le Cancer 
(SL22020605297), and Agence Nationale de la Recherche (ANR-ADSTEM and ANR-11-LABX-0028-01) to A.S., and the Agence Nationale de la Recherche (ANR-14-CE12-0007) to A.S. and A.M.

\section{References}

Ahn S, Joyner AL. 2004. Dynamic changes in the response of cells to positive hedgehog signaling during mouse limb patterning. Cell 118: 505-516.

Ahn Y, Sanderson BW, Klein OD, Krumlauf R. 2010. Inhibition of Wnt signaling by Wise (Sostdc1) and negative feedback from Shh controls tooth number and patterning. Development 137: 3221-3231.

Bandiera R, Vidal VP, Motamedi FJ, Clarkson M, Sahut-Barnola I, von Gise A, Pu WT, Hohenstein P, Martinez A, Schedl A. 2013. WT1 maintains adrenal-gonadal primordium identity and marks a population of AGP-like progenitors within the adrenal gland. Dev Cell 27: 5-18.

Benhamouche S, Decaens T, Godard C, Chambrey R, Rickman DS, Moinard C, Vasseur-Cognet M, Kuo CJ, Kahn A, Perret C, et al. 2006. Apc tumor suppressor gene is the 'zonation-keeper' of mouse liver. Dev Cell 10: 759-770.

Berthon A, Sahut-Barnola I, Lambert-Langlais S, de Joussineau C, DamonSoubeyrand C, Louiset E, Taketo MM, Tissier F, Bertherat J, Lefrancois-Martinez AM, et al. 2010. Constitutive $\beta$-catenin activation induces adrenal hyperplasia and promotes adrenal cancer development. Hum Mol Genet 19: 1561-1576.

Berthon A, Drelon C, Ragazzon B, Boulkroun S, Tissier F, Amar L, SamsonCouterie B, Zennaro MC, Plouin PF, Skah S, et al. 2014. WNT/ $\beta$-catenin signalling is activated in aldosterone-producing adenomas and controls aldosterone production. Hum Mol Genet 23: 889-905.

Bingham NC, Verma-Kurvari S, Parada LF, Parker KL. 2006. Development of a steroidogenic factor 1/Cre transgenic mouse line. Genesis 44: 419-424.

Chassot AA, Ranc F, Gregoire EP, Roepers-Gajadien HL, Taketo MM, Camerino G, de Rooij DG, Schedl A, Chaboissier MC. 2008. Activation of $\beta$-catenin signaling by Rspol controls differentiation of the mammalian ovary. Hum Mol Genet 17: 1264-1277.

Ching S, Vilain E. 2009. Targeted disruption of Sonic Hedgehog in the mouse adrenal leads to adrenocortical hypoplasia. Genesis 47: 628-637.

Comai G, Boutet A, Neirijnck Y, Schedl A. 2010. Expression patterns of the Wtx/Amer gene family during mouse embryonic development. Dev Dyn 239: 1867-1878.

de Lau W, Peng WC, Gros P, Clevers H. 2014. The R-spondin/Lgr5/Rnf43 module: regulator of Wnt signal strength. Genes Dev 28: 305-316.

Drelon C, Berthon A, Mathieu M, Martinez A, Val P. 2015. Adrenal cortex tissue homeostasis and zonation: a WNT perspective. Mol Cell Endocrinol 408: 156-164.

Freedman BD, Kempna PB, Carlone DL, Shah MS, Guagliardo NA, Barrett PQ, Gomez-Sanchez CE, Majzoub JA, Breault DT. 2013. Adrenocortical zonation results from lineage conversion of differentiated zona glomerulosa cells. Dev Cell 26: 666-673.

Hayashi S, McMahon AP. 2002. Efficient recombination in diverse tissues by a tamoxifen-inducible form of Cre: a tool for temporally regulated gene activation/inactivation in the mouse. Dev Biol 244: 305-318.

Heikkila M, Peltoketo H, Leppaluoto J, Ilves M, Vuolteenaho O, Vainio S. 2002. Wnt-4 deficiency alters mouse adrenal cortex function, reducing aldosterone production. Endocrinology 143: 4358-4365.
Hosen N, Shirakata T, Nishida S, Yanagihara M, Tsuboi A, Kawakami M, Oji Y, Oka Y, Okabe M, Tan B, et al. 2007. The Wilms' tumor gene WT1-GFP knock-in mouse reveals the dynamic regulation of WT1 expression in normal and leukemic hematopoiesis. Leukemia 21: 1783-1791.

Huang CC, Miyagawa S, Matsumaru D, Parker KL, Yao HH. 2010. Progenitor cell expansion and organ size of mouse adrenal is regulated by sonic hedgehog. Endocrinology 151: 1119-1128.

Iwatsuki K, Liu HX, Gronder A, Singer MA, Lane TF, Grosschedl R, Mistretta CM, Margolskee RF. 2007. Wnt signaling interacts with Shh to regulate taste papilla development. Proc Natl Acad Sci 104: 2253-2258.

Kazanskaya O, Ohkawara B, Heroult M, Wu W, Maltry N, Augustin HG, Niehrs C. 2008. The Wnt signaling regulator R-spondin 3 promotes angioblast and vascular development. Development 135: 3655-3664.

Kim KA, Kakitani M, Zhao J, Oshima T, Tang T, Binnerts M, Liu Y, Boyle B, Park E, Emtage P, et al. 2005. Mitogenic influence of human R-spondin1 on the intestinal epithelium. Science 309: 1256-1259.

Kim AC, Reuter AL, Zubair M, Else T, Serecky K, Bingham NC, Lavery GG, Parker KL, Hammer GD. 2008. Targeted disruption of $\beta$-catenin in Sf1-expressing cells impairs development and maintenance of the adrenal cortex. Development 135: 2593-2602.

King P, Paul A, Laufer E. 2009. Sh signaling regulates adrenocortical development and identifies progenitors of steroidogenic lineages. Proc Natl Acad Sci 106: 21185-21190.

Lustig B, Jerchow B, Sachs M, Weiler S, Pietsch T, Karsten U, van de Wetering M, Clevers H, Schlag PM, Birchmeier W, et al. 2002. Negative feedback loop of Wnt signaling through upregulation of conductin/axin2 in colorectal and liver tumors. Mol Cell Biol 22: 1184-1193.

Motamedi FJ, Badro DA, Clarkson M, Lecca MR, Bradford ST, Buske FA, Saar K, Hubner N, Brandli AW, Schedl A. 2014. WT1 controls antagonistic FGF and BMP-pSMAD pathways in early renal progenitors. Nat Commun 5: 4444.

Park JS, Ma W, O’Brien LL, Chung E, Guo J, Cheng JG, Valerius MT, McMahon JA, Wong WH, McMahon AP. 2012. Six2 and Wnt regulate self-renewal and commitment of nephron progenitors through shared gene regulatory networks. Dev Cell 23: 637-651.

Rocha AS, Vidal V, Mertz M, Kendall TJ, Charlet A, Okamoto H, Schedl A. 2015. The angiocrine factor Rspondin 3 is a key determinant of liver zonation. Cell Rep 13: 1757-1764.

Shaikh LH, Zhou J, Teo AE, Garg S, Neogi SG, Figg N, Yeo GS, Yu H, Maguire JJ, Zhao W, et al. 2015. LGR5 activates noncanonical Wnt signaling and inhibits aldosterone production in the human adrenal. I Clin Endocrinol Metab 100: E836-E844.

Shan J, Jokela T, Peltoketo H, Vainio S. 2009. Generation of an allele to inactivate Wnt4 gene function conditionally in the mouse. Genesis 47: 782-788.

Tomizuka K, Horikoshi K, Kitada R, Sugawara Y, Iba Y, Kojima A, Yoshitome A, Yamawaki K, Amagai M, Inoue A, et al. 2008. R-spondin1 plays an essential role in ovarian development through positively regulating Wnt-4 signaling. Hum Mol Genet 17: 1278-1291.

Walczak EM, Kuick R, Finco I, Bohin N, Hrycaj SM, Wellik DM, Hammer GD. 2014. Wnt signaling inhibits adrenal steroidogenesis by cell-autonomous and non-cell-autonomous mechanisms. Mol Endocrinol 28: 1471-1486.

Wood MA, Acharya A, Finco I, Swonger JM, Elston MJ, Tallquist MD, Hammer GD. 2013. Fetal adrenal capsular cells serve as progenitor cells for steroidogenic and stromal adrenocortical cell lineages in $M$. musculus. Development 140: 4522-4532. 


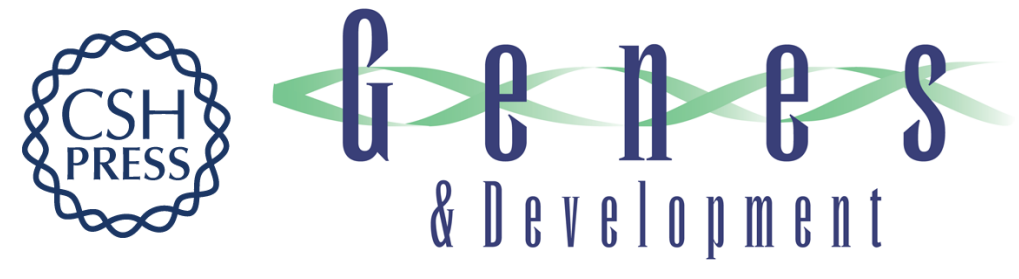

\section{The adrenal capsule is a signaling center controlling cell renewal and zonation through Rspo3}

Valerie Vidal, Sonia Sacco, Ana Sofia Rocha, et al.

Genes Dev. 2016, 30: originally published online June 16, 2016

Access the most recent version at doi:10.1101/gad.277756.116

\section{Supplemental http://genesdev.cshlp.org/content/suppl/2016/06/16/gad.277756.116.DC1 Material}

References This article cites 31 articles, 9 of which can be accessed free at: http://genesdev.cshlp.org/content/30/12/1389.full.html\#ref-list-1

Creative This article is distributed exclusively by Cold Spring Harbor Laboratory Press for the first Commons six months after the full-issue publication date (see

License http://genesdev.cshlp.org/site/misc/terms.xhtml). After six months, it is available under a Creative Commons License (Attribution-NonCommercial 4.0 International), as described at http://creativecommons.org/licenses/by-nc/4.0/.

Email Alerting Receive free email alerts when new articles cite this article - sign up in the box at the top Service right corner of the article or click here.

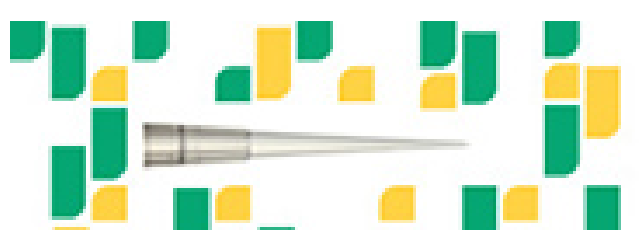

Focused on your science. 